\title{
Multiband Planar Inverted F Antenna (PIFA) for ISM, WLAN and WiMAX Applications
}

\author{
D. EL NABAOUI ${ }^{1}$, A. TAJMOUATI ${ }^{1}$, J. ZBITOU ${ }^{1}$, H. BENNIS $^{2}$, A. ERRKIK ${ }^{1}$, \\ L. ELABDELAOUI ${ }^{1}$, M. LATRACH ${ }^{3}$ \\ ${ }^{1}$ LMEET, FST of Settat, Hassan $1^{\text {st }}$ Univeristy, Settat, Morocco \\ ${ }^{2}$ TIM Research Team, EST of Meknes, Moulay Ismail University, Meknes, Morocco \\ ${ }^{3}$ Microwave Group, ESEO, Angers, France \\ Driss.elnabaoui@gmail.com
}

\begin{abstract}
This paper presents a new design of a multi-band inverted $\mathrm{F}$ antenna structure (PIFA) fed by a coaxial line. The design tool is the CST-MW software which uses the finite element method. To create new resonances frequencies it is necessary to insert slits of various forms on the radiation element. The final validated circuit is designed to operate in the Industrial Scientific and Medical (ISM 2.4 - 2.5GHz), Wireless Local Area Network (WLAN 5.15 - 5.35 GHZ) and Worldwide Interoperability for Microwave Acces (WiMAX 3.30 - 3.80). Obviously, it has been found that the radiation patterns of the antenna shown are similar to the bidirectional radiation pattern. For simulated The properties of the antenna, such as return losses and radiation patterns, we used CST-Mw Studio.
\end{abstract}

Keywords: PIFA antenna, multibands antennas, slottedPIFAs, Simulation.

\section{Introduction}

Currently, it requests wireless communication system technologies, which have the following attributes compact size, low profile, multi-band, high-bandwidth, etc.... In order to response the rapidly growing demand, an antenna should be responsible and operate in many frequency bands. Recently, multi-band antennas developments were improved thanks to the notion PIFA. Planar Inverted F Antenna (PIFA) is a linear Inverted F antenna (IFA) [1]. To increase the bandwidth and resonance frequency, the radiator element must be replaced by a plate. The reduced radiation behind the PIFA improves antenna performance in terms of gain and minimizes the wave produced due to power absorption [2-4]. We have a maximum gain in terms of polarization states like horizontal and vertical. The bandwidth can be adjusted if changing the height, length and width of the ground plane. To decrease the quality factor and to boost the bandwidth, many slits can insert in the ground plane. In medical applications, the main objective is to reduce the maximum size of the PIFA [5].

\section{Planar Inverted Antenna F (PIFA)}

Planar Inverted $\mathrm{F}$ antenna is developed from mono pole antenna. Inverted $\mathrm{L}$ is realized by folding down the mono pole in order to decrease the height of the antenna at the same time maintaining identical resonating length [6]. When feed is applied to the Inverted L, the antenna 
appears as Inverted F. The thin top wire of Inverted $\mathrm{F}$ is replaced by planar element to get the Planar Inverted F antenna. This sequence is clearly observable in Fig 1. [7-9]

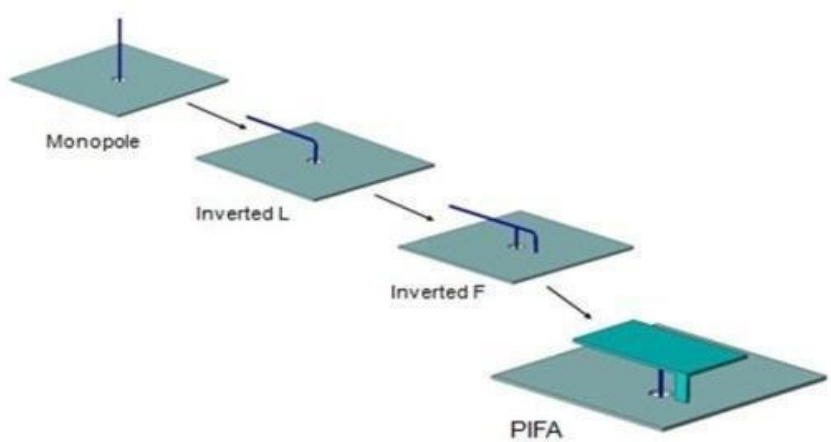

Fig. 1. PIFA from monopole

\subsection{Pifa Design}

PIFA consists of ground plane, radiating patch above the ground plane and shorting plane. A coaxial probe feed is given between the ground plane and patch element. Top radiating patch plane is folded at one edge of a patch and shorted to the ground plane to decrease the antenna length as shown in Fig 2 [10-12]. The size of the patch and resonating frequency can be determined by the following equations:

$$
\begin{gathered}
L_{p}+W_{p}-W=\frac{\lambda}{4} \\
f_{r} \times \lambda=\frac{C}{\sqrt{\varepsilon_{r}}} \\
f_{r}=\frac{C}{4\left(L_{p}+W_{p}-W\right) \sqrt{\varepsilon_{r}}}
\end{gathered}
$$

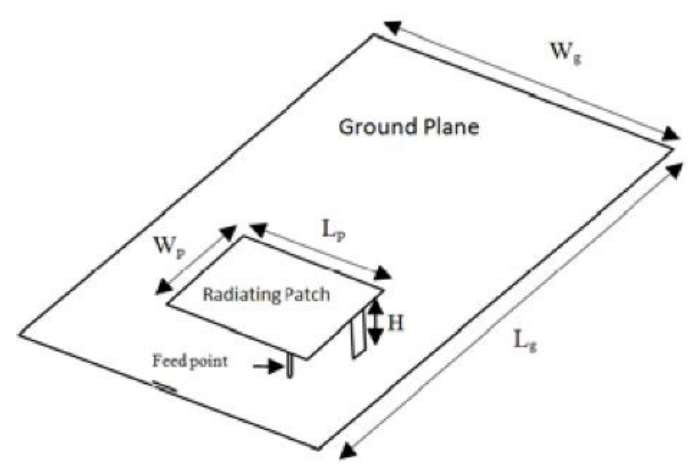

Fig. 2. Basic PIFA 
Where $\mathrm{Lp}=$ length of the patch, $\mathrm{Wp}=$ Width of the patch, $\mathrm{C}=$ Velocity of light, $\mathrm{cr}=$ dielectric constant, $\beta=$ wavelength. PIFA has moderate (or) high gain in both horizontal and vertical polarization. Generally, most of the wireless systems use vertical polarization. Even if transmitter antenna polarization is not known, still the signal is received with good strength. When antenna orientation is not fixed, a signal with good gain (greater than $10 \mathrm{~dB}$ ) is received and signal strength is calculated by summing up the horizontal and vertical components [13-15].

\section{Antenna Description}

The design of the proposed antenna is shown in Fig 3. It consists of patch plane, ground plane, shorting plate and feeding post connected to the ground plane. Between dielectric medium and patch plate, air is placed. Resonating frequency can be calculated if the initial patch and shorting pin sizes are known using equation (3).

The dimensions of PIFA are $50 \times 46 \mathrm{~mm}^{2}$ and are located $5 \mathrm{~mm}$ above the printed circuit board. The printed circuit board layer has a relative permittivity of 4.4 (FR4_epoxy) of size $93 \times 60 \times 0.5$ $\mathrm{mm}^{3}$. To provide an RF mass, the PCB is metallized on its back surface. Using optimization, PIFA is operating at $2.45 \mathrm{GHz}, 3.6 \mathrm{GHz}$ and $5.2 \mathrm{GHz}$ resonance frequencies to cover ISM, WiMAX and WLAN bandwidths. The proposed antenna is powered by a coaxial probe. The Ushaped slot is introduced on the patch plane to obtain the multi-band.

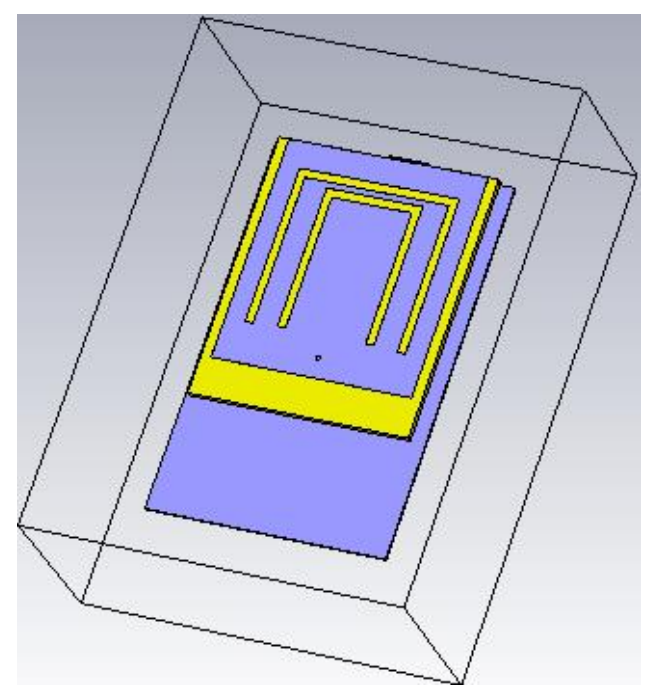

Fig. 3. PIFA design 
Antenna geometry is shown in Table 1 and antenna description is shown in Table 2.

Table 1. Dimension of the proposed antenna

\begin{tabular}{cc}
\hline Parameter & $\begin{array}{c}\text { Optimized } \\
\text { Value } \\
\text { (mm) }\end{array}$ \\
\hline Ws & 55 \\
Ls & 65 \\
H & 1.6 \\
Wp & 50 \\
Lp & 55.5 \\
t & 0.035 \\
Wg & 60 \\
Lg & 93 \\
Lshort & 5 \\
tg & 0.5 \\
Wshort & 10 \\
Ri & 0.5 \\
Vcentre & 18 \\
Ro & 1.637 \\
Wslot1 & 40 \\
Lslot1 & 39 \\
Wslot2 & 24 \\
Lslot1 & 35 \\
Lv & 3 \\
\hline
\end{tabular}

Table 2. Antenna description

\begin{tabular}{cc}
\hline Shape & Rectangular \\
\hline $\begin{array}{c}\text { Frequency of } \\
\text { operation }\end{array}$ & ISM \\
WLAN \\
WiMAX
\end{tabular}


The dimensions of different slots are clearly mentioned in the front view of antenna as shown in Fig 4.

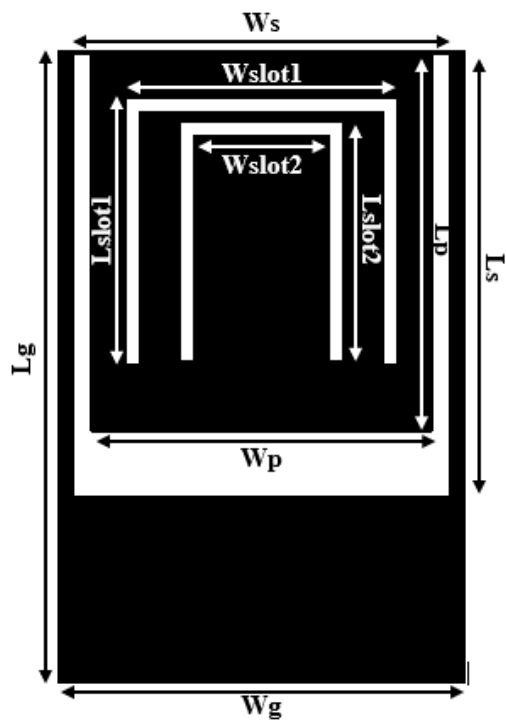

(a)

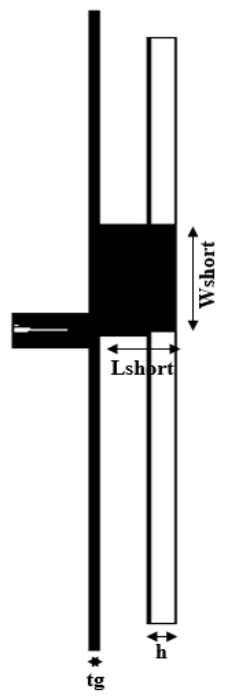

(b)

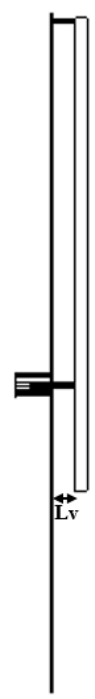

(c)

Fig. 4. Geometry of the proposed antenna: (a) front view, (b) top view, (c) side view

\section{Simulation Results}

The Planar Inverted F antenna was analyzed and optimized with the CST Microwave Studio. Since generally PIFA is a high frequency device driven model is used while designing antenna in CST Microwave Studio. The simulation results in all cases were swept over a frequency range between 2 and $7 \mathrm{GHz}$.

\subsection{Return Loss}

Reflection coefficient of an antenna is an important parameter in any antenna design analysis. It gives the measure of how much amount of power will be reflected back from the antenna. It should be kept as minimum as possible.

The simulated result is shown in Figure 5, as we can see we have reached the suitable frequency bands as ISM, WLAN and WiMAX. 


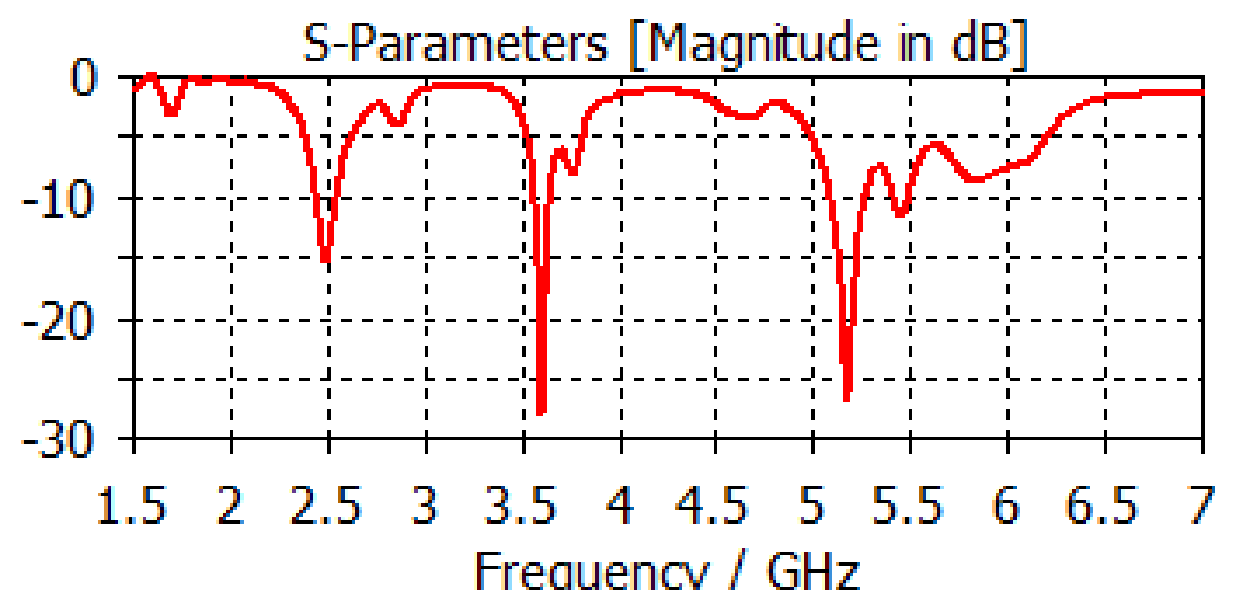

Fig. 5. Simulated Return Loss versus frequency

Table 3. Frequency bandwidth versus return-loss value

\begin{tabular}{cc}
\hline Frequency & Return Loss in dB \\
\hline $\mathbf{2 . 4 1 - 2 . 5 8}$ & -15.26 \\
$\mathbf{G H z}$ & \\
$\mathbf{3 . 5 1}-\mathbf{3 . 6 9}$ & -27.76 \\
$\mathbf{G H z}$ & \\
$\mathbf{5 . 0 4}-\mathbf{5 . 3 1}$ & -26.62 \\
$\mathbf{G H z}$ & \\
\hline
\end{tabular}

\subsection{Radiation Pattern}

The radiation pattern of an antenna is used to describe the 3-dimensional radiation characteristics.

Figure 6,7 and 8 presents the radiation pattern for different center frequencies, which give a stable radiation for different frequency bands. 
Farfield E-Field $(r=1 \mathrm{~m})$ Abs (Phi=90)

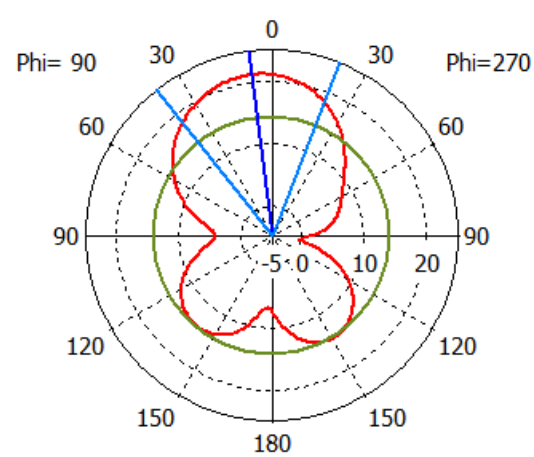

Theta / Degree vs. dBV/m

(a)
Farfield $\mathrm{H}$-Field $(\mathrm{r}=1 \mathrm{~m})$ Abs (Phi $=0)$

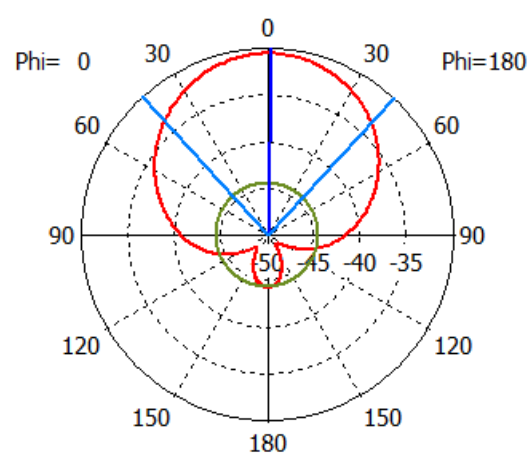

Theta / Degree vs. dBA/m (b)

Fig. 6. Radiation pattern of the proposed antenna at $2.45 \mathrm{GHz}$ in the (a) E-plane and (b) H-plane Farfield E-Field $(r=1 \mathrm{~m})$ Abs (Phi=90) Farfield H-Field $(r=1 \mathrm{~m})$ Abs $(\mathrm{Phi}=0)$

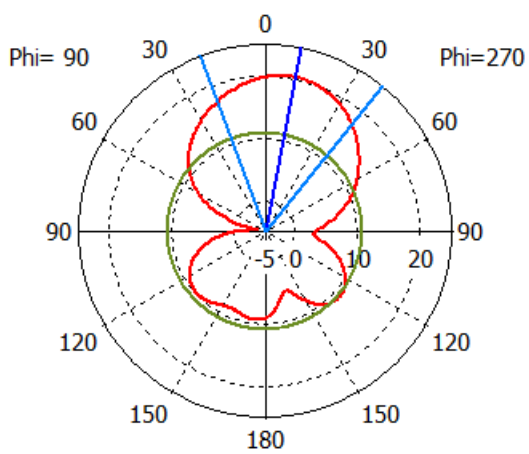

Theta / Degree vs. dBV/m

(a)

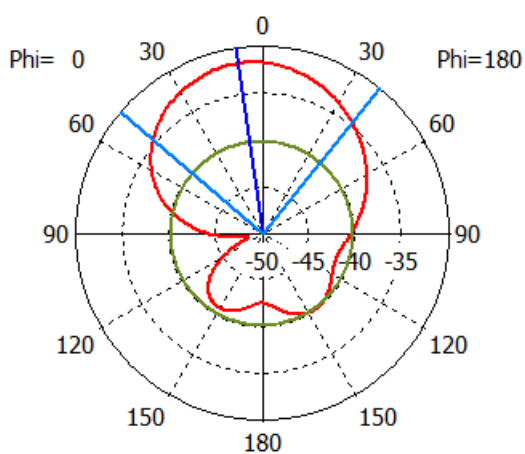

Theta / Degree vs. dBA/m

(b)

Fig. 7. Radiation pattern of the proposed antenna at $3.60 \mathrm{GHz}$ in the (a) E-plane and (b) H-plane 
Farfield E-Field $(r=1 \mathrm{~m})$ Abs $($ Phi=90)

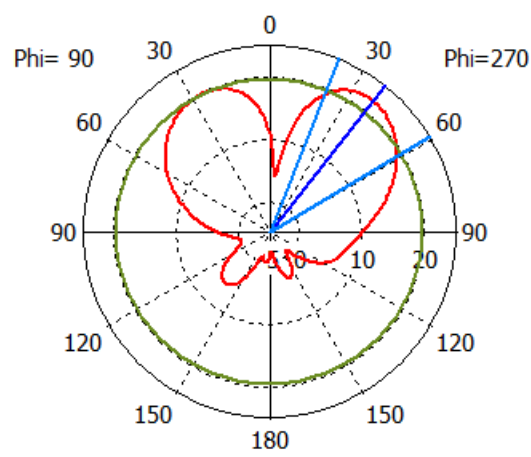

Theta / Degree vs. dBV/m

(a)
Farfield H-Field $(r=1 \mathrm{~m})$ Abs (Phi=0)

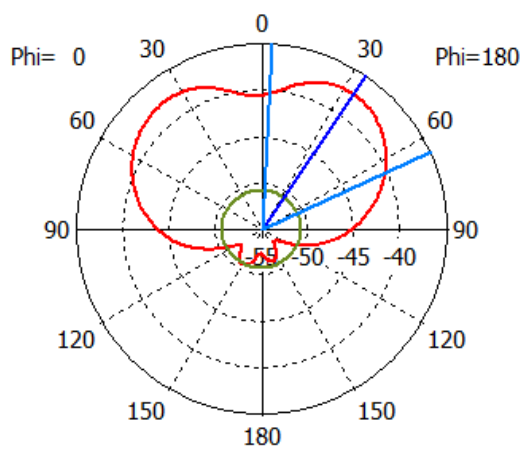

Theta / Degree vs. dBA/m

(b)

Fig. 8. Radiation pattern of the proposed antenna at 5.20 GHz in the (a) E-plane and (b) H-plane

Figure 9, illustrates the variation of the gain versus frequency. After the simulation, we have obtained the gain $6.75 \mathrm{~dB}$ at $2.45 \mathrm{GHz}, 5.58 \mathrm{~dB}$ at $3.6 \mathrm{GHz}$ and $7.14 \mathrm{~dB}$ at $5.2 \mathrm{GHz}$.

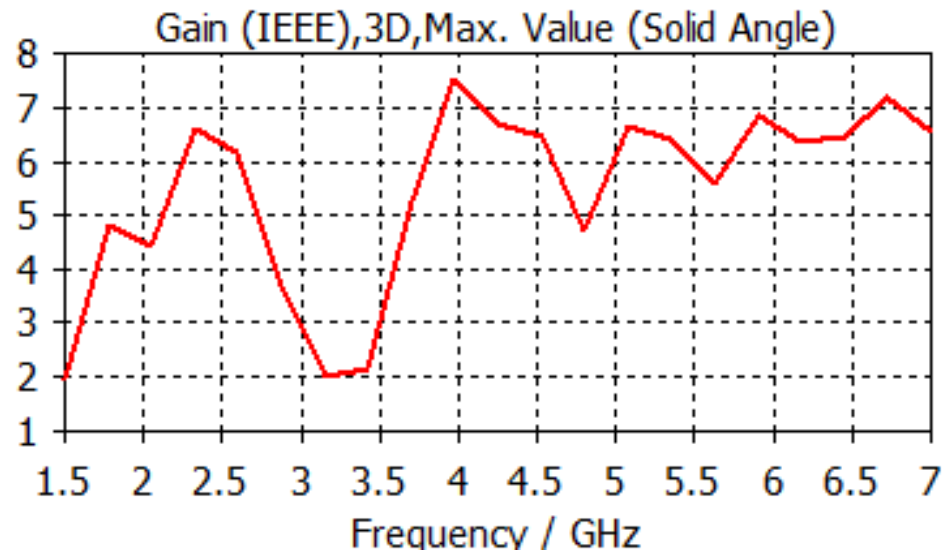

Fig. 9. Simulated gain of the proposed antenna

We present the simulated surface current distribution of the proposed antenna in the Fig. 10 at different frequencies. 


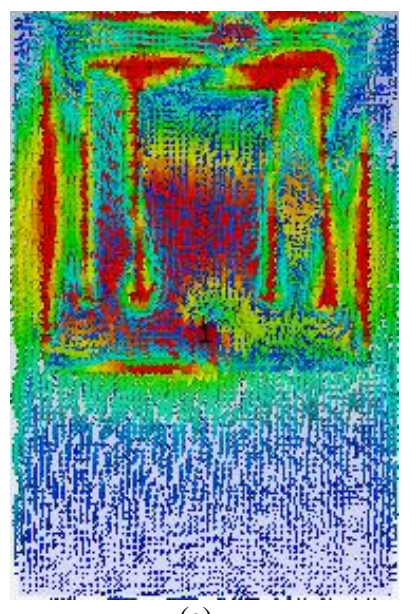

(a)

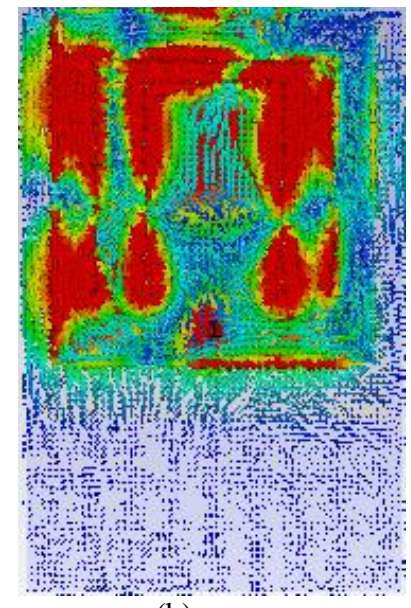

(b)

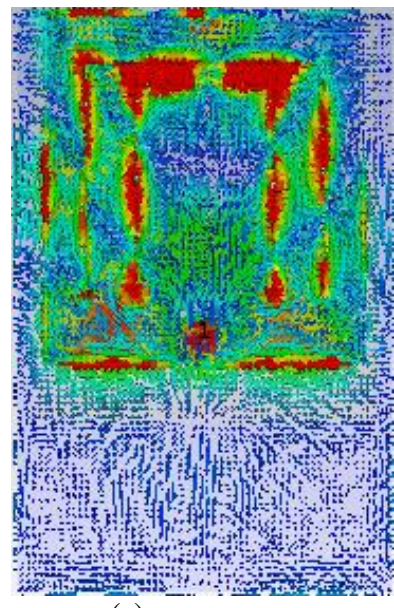

(c)

Fig. 10. Simulated surface current distribution at (a) $2.45 \mathrm{GHz}$, (b) $3.6 \mathrm{GHz}$ and (c) $5.2 \mathrm{GHz}$

\section{Conclusion}

In this work, we have validated into simulation a Planar Inverted Antenna (PIFA) based on the use of a coaxial line. To validate this antenna structure, we have used CST-MW. The PIFA covers a bandwidth of $170 \mathrm{MHz}(2.41-2.58 \mathrm{GHz}), 180 \mathrm{MHz}(3.51-3.69 \mathrm{GHz})$ and $270 \mathrm{MHz}(5.04-$ $5.31 \mathrm{GHz}$ ) and lower and higher bands with directivity of $7.22 \mathrm{~dB}, 7.49 \mathrm{~dB}$ and $8.24 \mathrm{~dB}$ at lower and higher resonating frequencies $2.45 \mathrm{GHz}, 3.60 \mathrm{GHz}$ and $5.20 \mathrm{GHz}$ respectively. This antenna structure has a stable bidirectional radiation pattern and good input impedance matching with a significant bandwidth.

\section{References}

[1] David M. POZAR "Microwave Engineering" Fourth Edition.

[2] Saad Wasmi Luhaib, Kaydar M. Quboa and Bareq M. Abaoy "Design and Simulation Dual-Band PIFA Antenna for GSM Systems" 9 thin ternational multi conference on systems 2012.

[3] Chenhui Jiang "Microwave and Millimeter-Wave Integrated Circuit Systems in Packaging" January $19,2010$.

[4] Adnan Iftikhar, Muhammad Nadeem Raftiq, "A Dual band balanced planar inverted F antenna (PIFA) for mobile applications" IEEE Proc-Microwave, Antennas Propagation, Vol.149, No,2, pp. 85$91,2013$.

[5] D. El Nabaoui, A. Tajmouati, J. Zbitou, A. Errkik, L. Elabdellaoui, A. Mediavilla "A New Design of a Low-Cost Multiband Fractal CPW-Fed Antenna", International Journal of Microwave and Optical Technology (IJMOT), Vol. 13, No. 1, PP. 1-7, January 2018.

[6] Constantine A. Balanis "Antenna Theory Analysis and Design" Third Edition.

[7] P. Nepa, G. Manara, A.A. Serra, g. Nenna. "Multiband PIFA for WLAN mobile terminals", IEEE Antennas Wireless Propagat Letters, 2005, vol.4, pp. 349 - 350.

[8] C. Mahatthanajatuphat, S. Saleekaw, P. Akkaraekthalin and M. Krairiksh "A Rhombic patch monopole Antenna with ModifiedMinkowski Fractal Geometry for UMTS, WLAN, and Mobile WIMAX Application”, Progress in Electromagnetics Research, PIER Vol. 89, pp. 57-74, 2009.

[9] G.Jeevagan navukarasu lenin, Ganesh babu.T, Rajkumar.R, Ramanathan.A "Design of an E Shaped Patch Antenna for GPS and IRNSS Application”, 2016 IEEE International Conference on Advanced Communication Control and Computing Technologies (ICACCCT), pp. 179-183, July 2016. 
[10] Antennas for all applications" 3rd edition by John D Krauss

[11] P. Salonen, M. Keskilammi, and M. Kivikoski, "Single-Feed Dual-Band Planar Inverted-F Antenna with U-Shaped Slot", IEEE Trans. Antennas and Propagat., Vol. 48, No. 8, pp. 1262-1264, Aug. 2000.

[12] Yamina BELHADEF and Nourediene BOUKLI HACENE "Design of New Multiband Slotted PIFA Antennas”, IJCSI International Journal of Computer Science Issues, Vol. 8, Issue 4, No 1, July 2011.

[13] Seyed Ehsan Hosseini, Amir Reza Attari and Aref Pourzadi "A Multiband PIFA with a Slot on the Ground Plane for Wireless Applications", International Journal of Information and Electronics Engineering, Vol. 3, No. 4, July 2013

[14] Naveen Kumar and Garima Saini «A Multiband Pifa with Slotted Ground Plane for Personal Communication Handheld Devices", International Journal of Engineering Research and Development, Volume 7, Issue 11, PP. 70-74, July 2013. 